2

I N S N

\title{
Resiliensi Pascabencana Tsunami
}

\author{
NURSAKINAH OKTAVIANA SASMITA ${ }^{*} *$ \& LENNY UTAMA AFRIYENTI 2 \\ 1 Universitas Mercu Buana, ${ }^{2}$ Universitas Bhayangkara Jakarta Raya
}

\begin{abstract}
ABSTRAK
Adanya bencana alam tsunami di wilayah Pandeglang dan sekitarnya hingga ke pesisir Lampung menyebabkan warga banyak yang mengalami kehilangan baik materi atau sanak saudara. Bencana alam telah memberikan dampak yang sangat signifikan terhadap fisik, psikologis, dan sosial. Kejadian tersebut mengakibatkan trauma kepada korban bencana. Upaya untuk bangkit dari kondisi mental yang tidak menguntungkan diperlukan kemampuan resiliensi. Ada tujuh kemampuan yang membentuk resiliensi yaitu; regulasi emosi, pengendalian impuls, optimisme, empati, causal analysis, efekasi diri, dan reaching out. Pada dasarnya, setiap orang mempunyai semua faktor tersebut. Namun, yang membedakan adalah bagaimana seseorang menggunakan dan memaksimalkan faktor tersebut agar berguna dalam menghadapi masa-masa sulit. Penelitian ini bertujuan untuk mengetahui tingkat resiliensi para korban tsunami di daerah Sumur, Pandeglang. Penelitian ini menggunakan metode kuantitatif. Populasi berjumlah 220 kepala keluarga dengan sampel sebanyak 50 orang. Skala yang digunakan adalah Resilience Scale dari Reivich yang berjumlah 56 item tetapi dalam penelitian ini hanya digunakan 21 item saja. Analisis data menggunakan regresi berganda menghasilkan 0,92 persen terhadap variabel resiliensi. Sedangkan variabel terbesar yang memengaruhi adalah causal variable, yang memberikan sumbangan sebesar 25,5 persen.
\end{abstract}

Kata kunci: bencana alam, tsunami, penyintas, resiliensi

\begin{abstract}
The tsunami in Pandeglang region to Lampung coastal area has caused many residents to experience loss of both material and relatives. Natural disasters have had very significant physical, psychological and social impacts. The incident caused trauma especially the survivors. Efforts to rise from an unfavorable mental state require resilience. There are seven abilities that make up resilience namely; emotional regulation, impulse control, optimism, empathy, causal analysis, self-effectation, and reaching out. Basically, humans have all these factors, but, how someone uses and maximizes these factors to deal with difficult times distinguishes one of us. This study aimed to determine the level of resilience of tsunami survivor in Sumur, Pandeglang. This was quantitative research. The population was 220 households with 50 samples. Resilience Scale by Reivich, was used. There were originally 56 items, but this research only used 21 of them. The data were analyzed using multiple regression, yielding 0.92 per cent of the resilience variabel. Variabel with the biggest influence was causal variabel, which contributed 25.5 per cent.
\end{abstract}

Keywords: natural disaster, tsunami, survivor, resilience 
INSAN Jurnal Psikologi dan Kesehatan Mental, 2019, Vol. 4(2), 94-101, doi: 10.20473/jpkm.v4i22019.94-101 Dikirimkan: 28 November 2019 Diterima: 25 Januari Diterbitkan: 2 April 2020

Editor: Rizqy Amelia Zein

*Alamat korespondensi: Universitas Mercu Buana Jakarta, Meruya Selatan

Pos-el: mail2sakinah@gmail.com

Naskah ini merupakan naskah dengan akses terbuka dibawah ketentuan the Creative Common Attribution License (http://creativecommons.org/licenses/by/4.0), sehingga penggunaan, distribusi, reproduksi dalam media apapun atas artikel ini tidak dibatasi, selama sumber aslinya disitir dengan baik.

\section{P E N D A H U L U A N}

Indonesia disebut adalah negara kepulauan dan berada pada cincin api pasifik. Hal ini berdampak pada banyaknya bencana alam karena aktivitas tektonik seperti gempa bumi, banjir, longsor, atau tsunami. Longsor, gunung meletus, dan tsunami adalah bencana yang sulit diprediksi. Bencanabencana tersebut mengakibatkan hilangnya tempat tinggal, lumpuhnya ekonomi, rusaknya fasilitas pendidikan, sulitnya akses pangan dan air bersih. Dalam keadaan minimnya pangan dan air bersih, pengungsi dan penyintas perlu berbagi satu sama lain. Hal ini dapat berlangsung hingga dua tahun hingga keadaan pulih kembali. Dalam konteks kesehatan mental, bencana alam dapat mengakibatkan trauma bagi penyintas. Pasca tsunami, banyak lembaga yang berdatangan guna memberikan penyuluhan. Hal tersebut diupayakan guna memperkuat daya tahan resiliensi penyintas.

Bencana alam memberikan dampak yang sangat signifikan terhadap fisik, psikologis dan sosial. Upaya untuk bangkit dari kondisi mental yang tidak menguntungkan diperlukan kemampuan resiliensi (dikutip dalam Satria dan Sari, 2017). Ada tujuh kemampuan yang membentuk resiliensi, yaitu; regulasi emosi, pengendalian impuls, optimisme, empati, causal analysis, efikasi diri, dan reaching out. Pada dasarnya, setiap orang mempunyai semua faktor tersebut. Namun, yang membedakan adalah bagaimana seseorang mempergunakan dan memaksimalkan faktor tersebut untuk menghadapi masamasa sulit (Reivich dan Shatte, 2002). Dalam penelitian yang dilakukan Ariviyanti dan Pradoto (2014), terdapat 9 faktor yang diidentifikasi meningkatkan resiliensi. Tiga faktor yang paling berpengaruh di antaranya adalah faktor peninggian rumah, peninggian jalan serta adanya organisasi sosial yang peduli lingkungan, dan tanggap bencana.

Dalam kasus bencana tsunami di Pandeglang, Kecamatan Sumur adalah lokasi dengan dampak terparah dan akses tersulit. Bupati Pandeglang menyampaikan bahwa ada 63 korban meninggal, dan hampir 8000 orang perlu pertolongan (Hariyanto, 2018). Di hari ketiga penanganan tsunami, BNPB mencatat 429 orang meninggal dunia, 1485 luka-luka, dan ratusan bangunan rusak berat. Hal ini mengakibatkan akses jalan menuju tempat lokasi tsunami terparah mengalami gangguan (Hariyanto, 2018).

Penelitian yang dilakukan Sakti dan Sari (2017) menemukan bahwa tingkat resiliensi untuk siaga di rawan bencana adalah sekitar 63 persen. Artinya, tingkat resiliensi siaga bencana cukup tinggi. Sedangkan dalam penelitian Pasudewi (2012), resiliensi remaja binaan Bapas ada dalam kategori sedang sebesar 82,76 persen. Persentase tersebut hanya untuk lingkungan remaja binaan saja, belum meluas untuk remaja di daerah pesisir atau rawan bencana tsunami. Penelitian Nur Jannah dan Rohmatun (2018) menemukan bahwa semakin besar dukungan sosial yang diterima penyintas, maka semakin baik pula resiliensinya. 
Sedangkan penelitian yang dilakukan oleh Taufik dkk. (2014), anak-anak menunjukkan kemampuan yang baik dalam impulse control, optimisme, dan causal analysis. Di sisi lain, kemampuan yang tergolong rendah adalah regulasi emosi, empati, self efficacy, dan reaching out. Penelitian yang dilakukan Cintakawati dan Masykur (2006) menemukan hasil bahwa selain faktor-faktor umum yang harus ada di dalam resiliensi, religiusitas juga termasuk faktor penting yang harus ada agar dapat bangkit dan bertahan dari keterpurukan yang dialami akibat gempa. Lebih lanjut, penelitian Ifdil dan Taufik (2012) yang menemukan bahwa resiliensi siswa sangat penting untuk ditingkatkan dan dikembangkan. Oleh karena itu, para penyintas membutuhkan pembekalan dalam meningkatkan kemampuan resiliensi mereka

Pembahasan tentang resiliensi penting untuk dilakukan lebih-lebih bagi penyintas. Oleh karena itu, peneliti ingin meneliti bagaimanakah resiliensi yang ada di pesisir Pandeglang dan berapa tingkat resiliensi orang dewasa di sekitar Sumur.

\section{Aspek-aspek resiliensi}

a. Regulasi emosi adalah kemampuan untuk tetap tenang di bawah tekanan. Orang yang resilien dapat mengontrol emosi, khususnya ketika berhadapan dengan kesulitan dan tantangan.

b. Pengendalian impuls adalah kemampuan mengendalikan keinginan, dorongan, kesukaran serta tekanan yang muncul dari dalam diri seseorang. Orang yang dapat mengontrol impulsnya adalah orang yang mampu mencegah kesalahan pemikiran sehingga dapat memberikan respons yang tepat pada permasalahan yang dihadapi.

c. Analisis kausal adalah kemampuan seseorang dalam mengidentifikasi penyebab masalah yang akurat. Jika ia tidak dapat mengidentifikasi, ia cenderung mengulang kesalahan yang sama.

d. Efikasi diri adalah keyakinan pada kemampuan diri untuk menghadapi dan memecahkan masalah dengan efektif. Dengan efikasi diri tinggi, orang meyakini diri untuk mampu berhasil dan sukses serta memiliki komitmen dalam memecahkan masalah.

e. Optimisme adalah kemampuan untuk tetap positif tentang masa depan dan realistis dalam merencanakan. Optimisme mengimplikasikan bahwa orang percaya bahwa ia dapat menangani masalah yang muncul di masa yang akan datang.

f. Empati adalah kemampuan untuk membaca perilaku orang lain dengan memahami tanda-tanda psikologis dan emosi serta membangun relasi yang lebih baik. Orang ini dapat membaca tandatanda non-verbal orang lain seperti ekspresi wajah, nada suara, bahasa tubuh, dan lainnya.

g. Mencapai yang positif adalah kemampuan untuk meningkatkan aspek positif dari kehidupan dan berani mengambil kesempatan dan tantangan baru. Resiliensi tidak hanya penting untuk pengalaman hidup yang negatif dari trauma tapi juga memperdalam hubungan dan mencari pengalaman baru.

\section{Hipotesis}

Berikut ini adalah hipotesis yang diuji dalam penelitian:

a. Ada pengaruh antara regulasi emosi dengan variabel resiliensi

b. Ada pengaruh antara pengendalian impuls dengan variabel resiliensi

c. Ada pengaruh antara analisis kausal dengan variabel resiliensi

d. Ada pengaruh antara efikasi diri dengan variabel resiliensi

e. Ada pengaruh antara optimis dengan variabel resiliensi 
f. Ada pengaruh antara empati dengan variabel resiliensi

g. Ada pengaruh antara mencapai yang positif dengan variabel resiliensi

\section{E T O D E}

\section{Partisipan}

Populasi dalam penelitian ini adalah masyarakat pesisir di desa Sumber Jaya, Sumur, Pandeglang yang tinggal di hunian sementara dengan total 220 kepala keluarga. Setelah peneliti berada di lapangan, data yang disebar adalah 220. Namun setelah dilakukan penyeleksian, banyak data yang gugur sehingga hanya diperoleh 50 orang partisipan.

\section{Pengukuran}

Metode pengumpulan data dilakukan dengan menyebarkan kuesioner ke penduduk yang sudah dipilih. Alat Ukur yang digunakan adalah Alat Ukur Resiliensi dari Reivich. Dari jumlah asli 56 item, dengan pertimbangan penggunaan pada kalangan masyarakat pesisir, maka peneliti melakukan pengujian validitas terlebih dahulu untuk mengurangi jumlah item. Try out tersebut menghasilkan validity range sebesar 0,2 - 0,7 dengan reliabilitas 0,7. Artinya, alat ukur tersebut layak digunakan. Setelah itu dilakukan try out uji keterbacaan, jumlah item dikurangi menjadi 21.

\section{Analisis data}

Metode analisis yang digunakan dalam penelitian ini adalah regresi berganda menggunakan SPSS versi 20. Analisis ini guna mengukur faktor mana yang paling mendukung resiliensi para korban bencana di Sumur.

Analisis deskriptif

\section{H A S I L P E N ELIT IAN}

Distribusi populasi penelitian berdasarkan jenis kelamin

Tabel 1. Distribusi populasi penelitian berdasarkan jenis kelamin.

\begin{tabular}{lcc}
\hline \multicolumn{1}{c}{ Jenis Kelamin } & N & Persentase \\
\hline Laki-laki & 24 & $48 \%$ \\
Perempuan & 27 & $52 \%$ \\
\hline
\end{tabular}

Dari tabel di atas, dapat dilihat bahwa perempuan lebih banyak tiga orang dibandingkan laki-laki tetapi tidak berbeda jauh. Data ini menunjukkan adanya keseimbangan partisipan laki-laki maupun perempuan.

Tabel 2. Distribusi populasi berdasarkan pendidikan

\begin{tabular}{lr}
\hline Pendidikan & Jumlah \\
\hline SD & 18 \\
SMP & 20
\end{tabular}

INSAN Jurnal Psikologi dan Kesehatan Mental 2019, Vol. 4(2), 94-101 
Tabel di atas menunjukkan jumlah sampel yang berpendidikan SMP lebih banyak daripada strata pendidikan lainnya.

Tabel 3. Distribusi populasi berdasarkan pada pekerjaan

\begin{tabular}{lc}
\hline Pekerjaan & N \\
\hline Ibu Rumah Tangga & 24 \\
Nelayan & 11 \\
Wiraswasta & 15 \\
\hline
\end{tabular}

Tabel di atas menunjukkan pekerjaan warga Sumur. Ibu rumah tangga adalah pekerjaan paling banyak yang mungkin pada saat pengumpulan data, beberapa kelompok jenis pekerjaan lain tidak berada di lokasi.

Tabel 4. Distribusi perolehan kategorisasi data tahapan resiliensi

\begin{tabular}{lll}
\hline Rendah & $\mathrm{X}<$ mean $-1 \mathrm{X}$ SD & $24 \%$ \\
\hline Sedang & $<\mathrm{X}<$ mean $+1 \mathrm{X} \mathrm{SD}$ & $62 \%$ \\
\hline Tinggi & $\mathrm{X}<$ mean $+1 \mathrm{X}$ SD & $14 \%$ \\
\hline
\end{tabular}

Hasil analisis deskriptif menunjukkan bahwa 62 persen orang memiliki resiliensi sedang, 24 persen rendah, dan 14 persen yang kategori tinggi. Hal ini masih perlu ditinjau ulang dalam setahun ke depan guna mengetahui kelanjutan dari resiliensi tersebut.

Selanjutnya, peneliti melakukan uji regresi ganda pada setiap variabel. Langkah pertama, untuk mengetahui dampak dari seluruh independent variabel terhadap resiliensi. Berdasarkan hasil uji regresi berganda, model cukup tepat (fit) menggambarkan data $\left(F(7,40)=74.917, p=0.00, R^{2}=0.929\right)$. Dari uji regresi, diketahui bahwa $R^{2}$ adalah 0.929 atau sebesar 92.9 persen. Artinya, model dapat menjelaskan varians resiliensi sebanya 92.9 persen, sedangan sisanya dijelaskan oleh variabel yang lain. Langkah terakhir adalah melihat parameter di dalam model. Informasi mengenai parameter dalam model dapat dilihat di Tabel 5.

Tabel 5. Koefisien Regresi tiap variabel independen

\begin{tabular}{lccc}
\hline \multicolumn{1}{c}{ Variabel } & B & T & p \\
\hline Regulasi Emosi & .140 & 2.093 & .043 \\
Impulse Control & .268 & 4.19 & .000 \\
Optimisme & .270 & 3.984 & .000 \\
Causal & .237 & 3.416 & .002 \\
Empati & -0.05 & -0.776 & .443 \\
Self Efficacy & -0.185 & -2.978 & .005 \\
Reaching out & .567 & 7.668 & .000 \\
\hline
\end{tabular}

Jika kita lihat dari tabel di atas, maka hanya variabel empati yang tidak signifikan dengan nilai signifikansi .443 ( $p>0.05)$. Sedangkan variabel lainnya termasuk signifikan karena nilai kurang dari 0.05. Dengan demikian, dapat disusun persamaan regresinya sebagai berikut: 
Resiliensi $=-6.257+.140 *$ Regulasi Emosi $+.268 *$ Impulse Control $+.270 *$ Optimis $+.237 *$ Causal $-.05 *$ Empati - .185*Self Efficacy $+.567 *$ Reaching Out

\section{I S K U S I}

Penelitian ini bertujuan untuk mengetahui tingkat resiliensi para korban tsunami di daerah Sumur, Pandeglang. Metode penelitian menggunakan metode kuantitatif. Populasi dalam penelitian ini 220, namun yang terpakai hanya 50 sampel. Hal ini dikarenakan beberapa hal, salah satunya adalah beberapa sampel kurang mengerti bahasa Indonesia. Umumnya mereka menggunakan bahasa sunda sebagai bahasa daerah mereka. Jadi, ketika di lapangan, ada dua orang dari penduduk setempat yang mengartikan kembali dalam bahasa Sunda. Skala yang digunakan adalah Resilience Scale dari Reivich yang berjumlah 56 item, namun dalam penelitian ini hanya akan menggunakan 21 item saja. Analisis data menggunakan regresi ganda menghasilkan bahwa sebesar 92,9 persen sumbangan yang diberikan keseluruhan aspek resiliensi, sedangkan sisanya dipengaruhi oleh aspek lainnya.

Hasil penelitian ini memberikan semacam wacana dan informasi mengenai resiliensi. Dapat dilihat bahwa nilai yang terbesar pada resiliensi korban tsunami di daerah Sumur adalah analisis kausal. Analisis kausal adalah kemampuan seseorang dalam mengidentifikasi penyebab masalah yang akurat. Pada usia dewasa, manusia mampu mengolah kognitifnya dengan berpikir logis. Ciri khas yang melekat pada usia dewasa adalah kemampuan berpikir reflektif dimana pada masa ini ada pertimbangan aktif, persisten dan hati-hati terhadap informasi atau keyakinan mengenai bukti-bukti yang mendukung mereka dan mengarahkan pada keputusan yang dibuat. Pemikir reflektif dapat menciptakan sistem kecerdasan kompleks yang menyatukan konflik ide-ide atau pertimbangan yang muncul (Papalia \& Feldman, 2014). Hal ini sejalan dengan penelitian yang disampaikan oleh Stenberg (1988) bahwa kemampuan kognitif yang baik mengimplikasikan kemampuan analitikal, kreativitas dan pemecahan masalah yang baik pula serta dapat diimplementasikan pada kehidupan yang sesungguhnya.

Hal berikutnya adalah regulasi emosi, dimana kondisi ini terkait dengan kemampuan untuk tetap tenang di bawah tekanan. Orang yang resilien dapat mengontrol emosi, khususnya ketika berhadapan dengan kesulitan dan tantangan. Mereka mampu mengubah emosi negative menjadi lebih positif dan meningkatkannya. Orang yang resilien mampu mengendalikan emosi mereka khususnya saat berada pada masa sulit dan menghadapi tantangan yang mungkin muncul namun mereka tetap fokus pada tujuan (Reivich \& Shatte, 2002).

Selain itu pencapaian yang positif, impulse control, perasaan optimis, dan self-efficacy memberikan dampak yang besar pada individu yang resilien. Ini sejalan dengan penelitian yang disampaikan oleh Grotberg (1995) mengenai resiliensi bahwa ada tiga hal yang mendasar dari pribadi tersebut diantaranya, dukungan eksternal dan sumber daya, internal dan kekuatan personal, social dan kemampuan interpersonal.

\section{S I M P U L A N}

Berdasarkan hasil penelitian dan pembahasan, maka dapat ditarik kesimpulan bahwa regulasi emosi, impulse control, optimisme, causal, self-efficacy, reaching out, dapat membantu resiliensi para korban tsunami, namun tidak halnya dengan empati karena tidak berpengaruh signifikan terhadap resiliensi korban. 
Hasil penelitian ini dapat digunakan sebagai bagian dari rencana pelaksanaan terapi psikologis khususnya terkait dengan Cognitive Behavioral Therapy, Dialectical Behavioral Therapy agar mampu melihat individu dalam menerima bencana serta bangkit atas apa yang telah terjadi. Hasil penelitian ini juga perlu diperdalam, khususnya resiliensi pada orang dewasa dengan melihat variabel lain seperti mindfulness, grateful dan forgiveness agar studi selanjutnya akan lebih komprehensif dan dapat menjadi acuan bagi individu dalam menjalani kehidupan selanjutnya pasca bencana.

\section{U C A P A N T ERIMA KASIH}

Peneliti mengucapkan terimakasih pada Universitas Mercu Buana yang telah mendukung pendanaan penelitian ini serta peran serta tokoh terkait lainnya, di Sumur, Pandeglang,

\section{DEKLARASI POTENSI TERJADINYAKONFLIK KEPENTINGAN}

Nursakinah Oktaviana Sasmita dan Lenny Utama Afriyenti tidak bekerja, menjadi konsultan, memiliki saham, atau menerima dana dari perusahaan atau organisasi mana pun yang akan mengambil untung dari naskah ini, dan telah mengungkapkan bahwa ia tidak memiliki afiliasi selain yang telah disebut di atas.

\section{PUS TAKA ACUAN}

Ariviyanti, N., \& Pradoto, W. (2014). Faktor-faktor yang meningkatkan resiliensi masyarakat dalam menghadapi bencana Rob, Kelurahan Tanjung Mas Semarang. Teknik PWK (Perencanaan Wilayah Kota), 3(4), 993-1002. https://ejournal3.undip.ac.id/index.php/pwk/article/view/6803

Bogar, C. B. \& Hulse -Killacky, D. (2006). Resilliency determinants and resiliency process among female adult survivorsof childhood sexual abuse. Journal of counceling and development, 84 (3), 318-327.

Cintakawati, A., \& Masykur, A. (2014). Resiliensi Pada Wirausahawan Penyintas Gempa Bumi 27 Mei 2006 Di Kecamatan Wedi Kabupaten Klaten. Empati, 2(3), 213-222. Diakses melalui https://ejournal3.undip.ac.id/index.php/empati/article/view/7323/7083

E. Papalia, D., \& Duskin Feldman, R. (2014). Menyelami Perkembangan Manusia: Experience Human Development (12th ed.). Jakarta: Salemba Humanika.

Grotberg, E. (1995). A Guide to Promoting Resilience in Children: Strengthening the Human Spirit. The Netherlands: Bernard van Leer Foundation.

Hariyanto, I. (2018, December 26). Balada Sumur, Wilayah Terdampak Tsunami yang Sulit Dijangkau. Retrieved April 2019, from https://news.detik.com/berita/d-4358627/balada-sumur-wilayahterdampak-tsunami-yang-sulit-dijangkau

Ifdil, I., \& Taufik, T. (2012). Urgensi Peningkatan dan Pengembangan Resiliensi Siswa di Sumatera Barat. PEDAGOGI | Jurnal Ilmiah Ilmu Pendidikan, 12(2). Diakses melalui http://ejournal.unp.ac.id/index.php/pedagogi/article/view/2195/1819

Mutia, B., \& Sari, M. (2017). Tingkat Resiliensi Masyarakat di Area Rawan Bencana. Idea Nursing Journal, 8(2). Diakses melalui http://jurnal.unsyiah.ac.id/INJ/article/view/8818/7425 
Nur Jannah, S., \& Rohmatun, R. (2018). Hubungan antara dukungan sosial dengan resiliensi pada penyintas banjir Rob Tambak Lorok. Proyeksi, 13(1). https://doi.org/10.30659/jp.13.1.1-12

Reivich, Karen dan Shatte, Andrew (2002). The resilience factor, 7 essential skill for overcoming life's inevitable obstacles. Random House, inc. New York.

Siebert, A (2005). The resiliency advantage: Master change,thrive under pressure and bounce back from setbacks. San Fransisco: Berret-Koehler Publisher, Inc.

Sternberg, R.J. (1998a). Cupid's arrow. New York: Cambridge University Press

Taufiq, R., Susanty, E., Titi S., D., \& Nurlina, E. (2014). Gambaran Resiliensi Anak Pasca Bencana Banjir di Desa Dayeuhkolot Kabupaten Bandung Jawa Barat. Wacana, 6(1). Diakses melalui https://jurnalwacana.psikologi.fk.uns.ac.id/index.php/wacana/article/view/5

Yeniar Pasudewi, C. (2012). Resiliensi pada remaja binaan BAPAS ditinjau dari Coping Stress. Journal of Social and Industrial Psychology, 1(2). Diakses melalui https://journal.unnes.ac.id/sju/index.php/sip/article/view/2639 